\title{
Do As I Say, Not As I Do
}

\author{
Kenneth E. Lloyd \\ University of Waikato
}

\begin{abstract}
The degree of agreement between responses to attitude questionnaires and responses in situations in which the content of the questionnaires is relevant is examined for the study of attitudes in general and for the study of environmental attitudes in particular. The observed low positive correlations of attitude and behaviour suggest that the notion that it is first necessary to change attitudes before one can change behaviour must be reevaluated. A review of the recent say-do correspondence literature is followed by a comparison of attitude-behaviour studies with say-do correspondence studies. A more empirical approach is urged for the future of environmental research which offers a unique arena for the study of attitudebehaviour congruence.
\end{abstract}

My title implies a commonsense recognition of a low, if not absent, correlation between what a person says he would do and what he actually does later. The sign and size of this correlation are important for psychologists whenever a response to a verbal statement (as in a clinical interview, a personality test or attitude scale) is considered indicative of how the respondent would behave in an actual situation involving the content described in the test item. The high frequency with which psychologists generally rely upon verbal report, rather than direct observation of the criterion behaviour, suggests less scepticism in psychological theory than in commonsense lore regarding the direction and magnitude of this correlation. Whereas the layperson's conclusions about the correlation may be based on the number of honest folk and liars encountered in a lifetime, the psychologist's conclusions are presumably based on the data available. But from the earliest investigations (La Pierre, 1934) through recent reviews (O'Riordon, 1976), the data support, at

This paper is reprinted with the kind permission of the New Zealand Psychological Society Inc. It was first published in the New Zealand Psychologist (1980, 9, 1-8) when the author was a Visiting Professor of Psychology at the Department of Psychology, University of Waikato. The author is now at the Department of Psychology, Central Washington University, Ellensburg, WA 98926, where requests for reprints can be sent. Thanks are due M. Foster, F. D. Klopfer, M. E. Lloyd, J. Quirke, J. Scown, and R. Siegert for a critical reading of a draft of this manuscript. best, a low positive correlation when verbal attitude statements are correlated with measures of actual behaviour in the presence of the object of the attitude. This paper discusses examples of the attitudebehaviour congruence problem from the overall attitude literature and specifically from the environmental psychology literature. A more general analysis of the problem includes examples from the recent correspondence literature (Risley \& Hart, 1968) as well as a statement of how the correspondence literature can relate to the attitude literature.

\section{ATTITUDE-BEHAVIOUR CONGRUENCE}

Travelling across the United States with a Chinese husband and wife La Pierre (1934) noted the 250 restaurants and motels which fed and lodged them. In response to a later written query some $90 \%$ of the 128 proprietors who answered indicated that they would not serve Chinese after having, in fact, done so. In a later study, two young white women entered each of 11 restaurants in a fashionable suburban community asking for a table for three (Kutner, Wilkins, \& Yarrow, 1952). After the two whites were seated, the third experimenter, a black woman, entered and informed the head waiter/waitress that she was with a party already seated. The black was seated and served in all 11 restaurants. Two weeks later each restaurant was sent a letter requesting a reservation for a group of friends, some of whom were black. No 
restaurant responded. After seven days an experimenter telephoned each restaurant repeating the contents of the letter. All 11 restaurants refused the reservation. Ten of the 11 restaurants accepted reservations requested in a second call which did not mention blacks.

These examples are not unique. In a review of 31 studies, Wicker (1969) concluded that "taken as a whole, ... it is considerably more likely that attitudes will be unrelated or only slightly related to overt behaviors than that attitudes will be closely related to actions" (p. 65). Correlations between attitude scale scores and behaviour measures were rarely above +0.30 and often near zero, and were negative in four studies.

The congruence between attitude and behaviour as measured by psychologists seems to be positive in sign and small in size. The seriousness of this low degree of congruence is more apparent when we recognise the widespread acceptance of the notion among both laypeople and psychologists that if one is to change behaviour significantly then one should first change attitudes. This change-attitudethen-behaviour principle seems to rely upon a high positive attitude-behaviour correlation.

\section{CONGRUENCE OF \\ ENVIRONMENTAL ATTITUDES AND BEHAVIOUR}

Environmental attitudes have been selected for a more detailed analysis of congruence since environmental psychology is primarily involved with issues of great contemporary social concern, such as population density, use of space, litter, noise pollution, energy consumption, recycling, and small-scale community organisation (Bell, Fisher, \& Loomis, 1978; Tuso \& Geller, 1976). If governments and other social agencies are to heed what psychologists have to say on these issues then the validity of our statements becomes very important. Although a great amount of environmental data is based only upon verbal report to attitude questionnaires (see Environment and Behavior for examples), research in this area has varied widely in methodology. The environmental research abstracted here has been selected to illustrate this variation.

Maloney, Ward, and Braucht (1975) stated the change-attitude-then-behaviour principle clearly: "We must determine what the population knows, thinks, feels and actually does regarding ecology and pollution. These are necessary antecedent steps that must be made before an attempt can be made to modify critically relevant behaviors" (Maloney et al., 1975 , p. 787). Maloney et al. (1975) administered an environmental attitude scale to members of the Sierra Club (a private U.S.A. organisation devoted to preservation of pristine environments), to university students in three lower division psychology classes, and to adults with less than 13 years formal education. Statistically significant $F$-ratios between the responses of the three groups of subjects to the scale were obtained. The authors published their scale with no demonstration of changing either attitudes or behaviour.

Seeking to determine how universal the public concern for environmental issues might be, Tognacci, Weigel, Wideen, and Vernon (1972) administered a different ecological scale to a sample of residents in a medium sized U.S.A. city (Boulder, Colorado) located adjacent to an attractive physical environment. Correlations of respondents' scores on the scale with various demographic characteristics indicated a positive relationship between attitudes favourable to the environment and respondents who were more liberal, younger, and better-educated. The authors were pessimistic regarding a universal concern for environmental issues.

Hass, Bagley, and Rogers (1975) attempted to change attitudes in four groups of university students who were asked to read essays covering the future consumption of energy. The essays differed in their description of the noxiousness (high or low) of an energy crisis and of the probability (high or low) that a crisis was imminent. After reading the essay appropriate to their group, subjects indicated their degree of agreement with 
items on an opinion questionnaire. Two items queried subjects on the noxiousness of the energy issue; two items concerned the probability of an energy crisis; two asked subjects to assess the validity of the information in the essays; and four items asked subjects to state their intentions to do something about the energy situation. The following main effects of the analysis of variance were statistically significant: The mean scale scores of subjects reading high noxious essays and those reading high probability essays were higher than the mean scores of subjects reading low noxious essays or low probability essays; and the mean scores of subjects reading high noxious essays were higher than the mean scores of subjects reading low noxious essays on the four items concerning intentions to reduce energy consumption. There was no significant interaction. Although the mean scores on the 10-point opinion scale differed, the absolute size of these mean differences varied between 1.0 and 2.2 points. No measures of actual behaviour were obtained.

One potential problem with the experimental design often employed in attitude-behaviour congruence has been that the opinion items are often general in content while the actual behavioural situation tends to be very specific. That is, attitudinal measures frequently make broad and philosophical attitudes salient, whereas behavioural measures make specific and immediately personal attitudes salient. O'Riordon (1976) argues that low correlations between attitude and behaviour may therefore result from different sets of subattitudes being salient in the testing and behavioural situations. Weigel, Vernon, and Tognacci (1974) examined this confounding of general and specific measures with attitude-behaviour congruence by varying both the degree of specificity of questionnaire items and the number of different component responses to a criterion behaviour that subjects would make toward an actual commitment. Three attitude scales comprised items of high, medium, or low specificity of the topic. The component responses, in order of increasing ap- proach to the terminal behaviour, consisted of the respondents (1) signing a consent slip indicating their willingness to have their names given to the local Sierra Club; (2) their agreeing later to make an appointment to talk with a Sierra Club member; (3) their subsequent writing of a letter supporting the club or donating money to the club; and (4) their actually working on a club project or joining the Sierra Club. Of 141 subjects, 80 agreed to have their names given to the Sierra Club. During an intervening fivemonth period the experimenter coached 10 Sierra Club members in interviewing skills. These interviewers contacted 52 of the 80 willing respondents. The experimenter correlated the respondents' scores on each of the three attitude scales with their scores on the four component responses. The resulting correlations were highest (about +0.60 ) with the most specific attitude scale; middling (about +0.30 ) with the medium specific scale and lowest (about +0.10 ) with the most general attitude scale. The authors argued that attitudes can be "precursors of behavior" or "determinants of how a person will actually behave in his daily affairs" if the measure of attitude and the measure of actual behaviour are both sufficiently specific. They suggested that if the object of the attitude being studied is general then "the behavioral criterion should be equally general or comprehensive" (Weigel et al., 1974, p. 728). This statement is puzzling since it would be difficult to come up with a comprehensive measure of actual behaviour. Verbal behaviour may be general or specific, but actual behaviour quickly becomes very specific once an investigator tries to obtain reliable interobserver measures of it.

Bickman (1972) studied an example of a specific attitude-specific behaviour relation. Two empty soda cans were placed on the ground near a rubbish can on a campus. As each of 20 persons approached the first soda can and the rubbish can, a collaborator of the experimenter kicked the first soda can. A second collaborator of the experimenter then picked up the first soda can and placed it in the rubbish can. Each of the 20 ap- 
proaching persons was potentially exposed to a littering episode, to a corrective episode, and to a second soda can on the ground. None of the 20 persons either kicked or picked up the second soda can. This example contained only actual behaviour, no attitude component. In a second experiment an attitude component was added. Crumpled newspaper was placed on the ground in the path of subjects approaching a library or a private store near a university. A rubbish can was nearby. Three metres in front of the litter every fifth passerby was approached by an experimenter who queried, "Should it be everyone's responsibility to pick up litter when they see it or should it be left for people whose job it is to pick up?" (Bickman, 1972, p. 323). Of 409 students and 97 nonstudents who passed the litter, 94\% said it was everyone's responsibility to pick up litter and $1.4 \%$ ( 5 students and 3 nonstudents) picked up the newspaper. Bickman (1972, p. 324) concluded that environmental problems would not be solved "by simply influencing verbally expressed attitudes."

In the final study to be reviewed, Seligman and Darley (1977) measured the outcome of actual behaviour. The dependent variable was the kilowatt hours of electricity (KWH) consumed every 24 hours in each of 40 family living units. Householders whose electric meters were read daily were randomly assigned to Feedback and Control groups. During a Pretreatment experimental phase the group KWH/day means were not significantly different $(68.33 \mathrm{KWH} /$ day for Feedback vs. $69.14 \mathrm{KWH} /$ day for Control). During a Treatment experimental phase each household in the Feedback group was given daily feedback of their electricity consumption in the prior 24 hours; Pretreatment conditions were maintained in the Control group. During the Treatment phase the group KWH/ day means were significantly different (48.56 KWH/day for Feedback vs. 54.25 KWH/day for Control). Both groups decreased consumption during the Treatment phase; the Feedback group however decreased its mean consumption by a greater amount (19.77 KWH/day) than did the Control group (14.89 KWH/day). The result is consistent with some 18 other studies in which more than 200 U.S.A. households indicated savings in KWH consumption of between $10 \%$ and $30 \%$ (Lloyd, 1980). Savings of this magnitude are financially and socially significant for public conservation programmes. The importance of these studies is that socially significant decreases in consumption were brought about by providing feedback regarding consumption to householders after they had completed their consumption. No known changes in attitudes were measured. Of course, the fact that the investigators did not obtain measures of responses to an attitude questionnaire does not indicate that no such changes took place. Indeed, Seligman and Darley (1977) suggested about their study, ". . . attitudes favourable to conservation probably developed and helped to sustain the motivation to conserve." The Seligman and Darley study brings us full circle from the initial studies in which only responses to questionnaires were observed and actual behaviour was surmised (Maloney et al., 1975; Tognacci et al., 1972) to this last study in which only actual behavioural outcomes were observed and attitudes were surmised!

A recent review of attitude-behaviour congruence in the field of environmental psychology concluded that "in view of the information provided .... it seems desirable that questionnaire techniques should be reassessed very carefully indeed" (O'Riordon, 1976, p. 22). This conclusion resembles Wicker's cited above (1969, p. 65). Given such pessimism it may be prudent to rethink the change-attitude-then-behaviour principle.

Seligman and Darley (1977) may provide a basis for another analysis. Their design not only shifted the emphasis in environmental research from changing attitudes to changing behaviour, but also shifted the temporal relationship between the critical independent variable and the criterion behaviour. The feedback variable was introduced by the ex- 
perimenters at the end of each 24-hour period; it informed householders of their immediate past consumption. Doing so changed their behaviour in the next 24hour period. This feedback procedure must be distinguished from a prompting procedure in which the experimenter presents householders with information, inducements, and/or threats specifying how they should behave. In a review of 11 studies employing prompts (Lloyd, 1980), only two studies reported any significant effect on subsequent energy consumption. Positive effects occurred when different prompts (short slogans or messages) were presented daily to householders and, therefore, inadvertently followed some behaviour (Palmer, Lloyd, \& Lloyd, 1977). In the nine studies reporting no effects, prompts were presented once and the behaviour was measured for about two weeks afterwards. These procedures producing no effects resembled those most frequently employed by governments, parents, and teachers, and by experimenters attempting to change attitudes (e.g., Hass et al., 1975). The distinction between feedback and prompting is important because feedback is much more likely to alter the criterion behaviour than prompting.

\section{DO-SAY AND SAY-DO}

It is well established that feedback about both nonverbal and verbal behaviours can alter the future occurrence of those behaviours. Further, if the content of the verbal behaviour being changed is similar to the content of the nonverbal (or actual) behaviour being observed, then we have a paradigm resembling that of attitude-behaviour congruence. The difference is that there is no implication that either one causes or influences the other. The verbal behaviour and the nonverbal behaviour may be viewed as separate classes of responses whose development may or may not be independent.

Research on the correspondence between doing and saying is relatively recent. In an initial study two groups of 4and 5-year-old boys and girls enrolled in a nursery school were observed during a half hour free-play period and during a snack-and-juice period 1.5 hours later (Risley \& Hart, 1968). During free-play a variety of toys including paints and blocks were available. The teacher recorded the time each child began and finished playing with a given material during free-play. During snack-and-juice a teacher passed a basket of snacks to each of the six children seated on a rug. Two observers recorded all verbalizations by all children during snack-time. In a 15 day Baseline condition the teacher encouraged the children to talk by asking, "What did you do that was good today?", then passed the snack basket to each child as they raised their hands to speak. In a 25 day Reinforcement-for-Content condition "... the teacher in Group A reinforced with snack and praise any positive statement containing both the words 'I' and either 'blocks' or any form of the verb 'to build'; the teacher in Group B reinforced all positive statements containing both 'I' and any form of 'paint' used either as a noun or a verb" (Risley \& Hart, 1968, p. 269). The teacher never differentially reinforced the accuracy of any of the children's comments.

In a 27 day Reinforcement-for-Correspondence condition a child was given a snack only if she/he said "I painted" ("I built a house") and if she/he had actually used paint (blocks) during that morning's free-play period. The teacher responded "You really did" or "You didn't really, though, did you?" depending upon the accuracy of the child's statement.

Interobserver agreement on all children's responses in both periods exceeded $95 \%$ throughout the study. In Baseline children in Group A seldom played with blocks and seldom said they had; that is, doing and saying were in agreement by virtue of both occurring at a near zero frequency. In Reinforcement-for-Content, $100 \%$ (median) of the children said they had used blocks; $0 \%$ (median) had used blocks. In Reinforcement-for-Correspondence, $100 \%$ (median) of the children said they had used blocks and $100 \%$ (median) had used blocks; that is, correspondence was achieved by increasing 
doing to the level of saying. In Baseline in Group B, $0 \%$ (median) of the children said they had painted although $20 \%$ (median) had actually painted. In Reinforcement-for-Content, $100 \%$ (median) of the children said they had painted; $33 \%$ (median) had painted. In Reinforcement-forCorrespondence, $40 \%$ (median) of the children said they had painted; $25 \%$ (median) had painted; that is, some correspondence was achieved by decreasing saying to a level of near doing.

In a second experiment the three conditions of the first experiment (Baseline, Content, and Correspondence) were successively repeated for each of five freeplay activities. Correspondence was achieved more rapidly with each successive new activity. Apparently, saying eventually did lead to doing. In the later Content conditions the children began doing more often as their saying increased. This led to an inadvertent reinforcement of correspondence which in turn may have speeded up the entire process. The results of this study have been replicated with children by other investigators (Israel \& Brown, 1977; Israel \& O'Leary, 1973), with chronic adult psychiatric patients (Tracy, Briddell, \& Wilson, 1974), with university students (Sowers, Lloyd, \& Lloyd, 1977), and with doing responses other than play, e.g., sharing and praising (Rogers-Warren \& Baer, 1976) or studying (Sowers et al., 1977).

\section{CONGRUENCE AND CORRESPONDENCE}

Although these investigations were concerned with neither attitude-behaviour congruence nor energy consumption, and although their results neither explain nor eliminate the problems of attitude-behaviour congruence, an analysis of the similarities and differences of the two research areas should be heuristic. The say-do studies have been designed to observe two different response classes repeated by a small number of subjects over a large number of days (e.g., 12 children for 146 days in Risley \& Hart, 1968) while attitude studies have been designed to observe one response class emitted once by a large number of subjects over a short period of time (e.g., 60 students reading two short essays and filling out a 21 -item questionnaire during a 50-minute university class in Hass et al., 1975). Measures of actual behaviour have also been one time only and of short duration (e.g., one meal in a restaurant in Kutner et al., 1952, or a few minutes on the street in Bickman, 1972). Examination of the day-to-day data from both response classes (e.g., Risley \& Hart, 1968, Fig. 1, p. 270) suggests that if an experimenter were to sample the two response classes on only one day (as in attitude-behaviour studies) then the conclusion about correspondence could well vary from zero to $100 \%$ depending upon which day was sampled. Day-to-day variations in how individuals fill out attitude questionnaires or in how individuals behave in the actual behavioural situations rarely appear in the attitude literature. How do restaurant owners respond to a telephone request for reservations the sixth or tenth time? How do the same owners respond the sixth or tenth time they are approached by a black person?

Such data may not have been collected since the statistical estimate of the scales' reliability assume that with a sufficiently large number of subjects tested, the dayto-day variations will average out. Statistical assumptions aside, repeated measures of the same persons may indicate hitherto unmeasured day-to-day variability in attitude-behaviour congruence.

The attitude-behaviour studies have been designed to test some hypothesis or theory rather than to observe directly correspondence over time. The possibility of preferences changing over time has not been considered, although studies of self-control have clearly demonstrated that initial choices may vary as a function of the length of the delay between the choice and subsequent reinforcement (Ainslie, 1974; Deluty, 1978; Rachlin \& Green, 1972; Scown, 1977). A change in preference over time would seem to be a potential ingredient contributing to attitude-behaviour congruence. That is, a person could endorse (prefer) a favour- 
able attitude statement toward blacks at time $t$ and prefer a less favourable actual behaviour toward blacks at time $t+u$.

The say-do research is so far limited to the use of positive reinforcers to increase verbal behaviour or its correspondence with actual behaviour. Presumably punishment procedures could be employed to decrease high frequency verbal behaviour to correspond to a low frequency of doing. Social agents sometimes punish verbal behaviour which does not correspond to socially desirable nonverbal behaviour. Doing so should ". . . produce correspondence by suppressing the report of the socially desirable behaviour to the level of the occurrence of that desirable behaviour itself ... More beneficial to society might be, the production of correspondence by increasing socially desirable behaviour to the level of verbal report" (Risley \& Hart, 1968, p. 267).

Despite arguments to the contrary, the change-attitude-then-behaviour hypothesis has considerable appeal. It is far simpler to attempt to shape verbal behaviour than to deal with actual behaviour in some actual situation. It was simpler for Hass et al. (1975), for example, to present 60 students with two essays to read and a 21-item questionnaire to complete, than it was for Seligman and Darley (1977) to read the electricity kilowatt-hour meters of 40 householders for 36 days of pretreatment and 23 days of treatment. Finally, the change agent may only have access to the verbal behaviour and never have access to the criterion behaviour as, say, in the case of the political candidate who may talk to his constituents before election day but is forbidden to enter the voting booth with them. In sum it is relatively simple to engage someone in conversation; it would be nice if that conversation could guarantee subsequent occurrence of some actual behaviour.

A problem with the hypothesis seems to be the implied causal link between attitude and behaviour. Acceptance of a causal link essentially demands a high, positive correlation of attitude and behaviour. In the face of empirically presented low correlations authors consider ways of rationalising the discrepancy.
Such rationalisations abound in Wicker (1969) and in O'Riordon (1976). The problem is that one author's explanations of the correlations are as good as another's and that the two are likely to differ. Often the "explanations" include reference to unobservable entities (social forces, values, cognitions as in O'Riordon, 1976 , p. 27). Such appeals may seem to explain phenomena, but they leave unsolved any account of the unobservable entities themselves.

The possibility of a reverse link, namely, a change-behaviour-then-attitude principle, has been recognised for attitudes in general (Bem, 1972) and for environmental issues in particular (O'Riordon, 1976). Wicker (1969) suggested that correlations predicting attitudes from overt behaviour seemed to be higher than the reverse. A direct comparison of dosay sequencing (children played for 20 minutes and 40 minutes later said what they had played) with say-do sequencing (children said what they would play and 40 minutes later played for 20 minutes) indicated greater correspondence than the say-do sequence (Israel \& O'Leary, 1973). University students' baseline reporting of their actual studying 14 hours previously corresponded more with the studying than did their baseline planning correspond with their actual studying 6 hours later (Sowers et al., 1977; also see Israel, 1978).

Even approaching the problem with no causal bias leaves undecided which verbal behaviour and which actual behaviour to measure. From the great variety of verbal (V) and behavioural (B) response classes which the individual can emit, the experimenter may observe a low correlation between, say, V1 and B6 when, in fact, observation of V2 and B2 would have produced a high correlation. There may be more possible variations in verbal response classes that describe an actual behaviour than there are possible variations in the actual responses. For example, there are a relatively limited number of ways by which I can pile one block on another as compared to the number of ways I could tell you that I am planning to pile them. I could say I 
am going to pile them on their ends and do so, I could say that I am going to pile them on their corners and be unable to do so. I could say I believe in conserving energy and that I am going to drive my auto more slowly hereafter, and I might actually do so, but I could also say a number of other sentences about conserving energy and my petrol consumption might also decrease (if I drove more slowly). This greater flexibility of verbal behaviour over nonverbal behaviour may contribute in an unknown way to attitudebehaviour congruence.

\section{CONCLUSION}

This paper has reminded the reader of the lower than expected correlations observed between attitude and behaviour and has urged a serious questioning of the change-attitude-then-behaviour principle. The say-do correspondence literature represents a more empirical approach to the question of the degree of agreement among different response classes.

Social psychologists have selected for study attitudes toward socially potent issues (e.g., ethnic groups, sex, or war) rather than more neutral topics (e.g., ice cream). Doing so has increased the difficulty of obtaining a concomitant measure of the criterion behaviour. The environmental psychology literature would seem to offer a fruitful area in which to study variables related to attitude-behaviour congruence. The topic is emotionally and socially important (like relations among ethnic groups) and measures of dependent variables for both attitude and behaviour are readily available. Questionnaire items about the environment, sex, or war may be constructed with equal ease, but measuring actual changes in KWH of electricity or litres of petrol consumed would seem more accessible than behaviour changes in the boudoir or on the battlefield. A research effort on saydo correspondence in energy consumption might provide some insights into a persistent issue in social psychology as well as suggest some procedures that would induce us to increase the congru- ence of our saying and doing regarding energy consumption.

\section{REFERENCES}

Ainslie, G. W. (1974). Impulse control in pigeons. Journal of the Experimental Analysis of Behavior, $21,485-489$.

Bell, P. A., Fisher, J. D., \& Loomis, R. J. (1978). Environmental psychology. Philadelphia: Saunders.

Bem, D. J. (1972). Self-perception theory. In L. Berkowitz (Ed.), Advances in experimental social psychology (pp. 1-62). New York: Academic Press.

Bickman, L. (1972). Environmental attitudes and actions. Journal of Social Psychology, 87, 323324.

Deluty, M. F. (1978). Self-control and impulsiveness involving aversive events. Journal of Experimental Psychology: Animal Behavior Processes, 4, 250-266.

Environment and Behavior. (1969 to present). London: Sage Publications.

Hass, J. W., Bagley, G. S., \& Rogers, R. W. (1975). Coping with the energy crises: Effects of fear appeals upon attitudes toward energy conservation. Journal of Applied Psychology, 60, 754-756.

Israel, A. C. (1978). Some thoughts on correspondence between saying and doing. Journal of Applied Behavior Analysis, 11, 271-276.

Israel, A. C., \& Brown, M. S. (1977). Correspondence training, prior verbal training, and control of non-verbal behavior via control of verbal behavior. Journal of Applied Behavior Analysis, 10, 33-38.

Israel, A. C., \& O’Leary, K. D. (1973). Developing correspondence between children's words and deeds. Child Development, 44, 575-581.

Kutner, B., Wilkins, C., \& Yarrow, P. R. (1952). Verbal attitudes and overt behavior involving racial prejudice. Journal of Abnormal and Social Psychology, 47, 649-652.

La Pierre, R. T. (1934). Attitudes vs actions. Social Forces, 13, 230-237.

Lloyd, K. E. (1980). Reactions to a forthcoming energy shortage: A topic in behavioral ecology. In G. Martin \& J. G. Osbourne (Eds.), Helping in the community (pp. 25-54). New York: Plenum.

Maloney, M. P., Ward, M. P., \& Braucht, G. N. (1975). A revised scale for the measurement of ecological attitudes and knowledge. American Psychologist, 30, 787-790.

O'Riordon, T. (1976). Attitudes, behavior and environmental policy issues. In I. Altman \& J. F. Wohlwill (Eds.), Human behavior and environment: Advances in theory and research (Vol. 1, pp. 1-36). New York: Plenum.

Palmer, M. H., Lloyd, M. E., \& Lloyd, K. E. (1977). An experimental analysis of electricity conservation procedures. Journal of Applied Behavior Analysis, 10, 665-671.

Rachlin, H., \& Green, L. (1972). Commitment, 
choice and self control. Journal of the Experimental Analysis of Behavior, 17, 15-22.

Risley, T. R., \& Hart, B. (1968). Developing correspondence between the non-verbal and verbal behavior of preschool children. Journal of $A p$ plied Behavior Analysis, 1, 267-281.

Rogers-Warren, A., \& Baer, D. M. (1976). Correspondence between saying and doing: Teaching children to share and praise. Journal of Applied Behavior Analysis, 9, 335-354.

Scown, J. M. (1977). Choice and commitment: Some aspects of self-control in children. Unpublished master's thesis, University of Waikato, Hamilton, New Zealand.

Seligman, C., \& Darley, J. M. (1977). Feedback as a means of decreasing residential energy consumption. Journal of Applied Psychology, 62, 363368.

Sowers, J. A., Lloyd, K. E., \& Lloyd, M. E. (1977). The effects of a class-based point system on planned-actual study time and actual-reported study time correspondence. Journal of Personalised Instruction, 2, 43-46.
Tognacci, L. N., Weigel, R. H., Wideen, M. F., \& Vernon, D. T. A. (1972). Environmental quality: How universal is public concern? Environment and Behavior, 4, 73-86.

Tracy, D. A., Briddell, D. W., \& Wilson, G. T. (1974). Generalization of verbal conditioning to verbal and non-verbal behavior: Group therapy with chronic psychiatric patients. Journal of $A p$ plied Behavior Analysis, 7, 391-402.

Tuso, M. A., \& Geller, E. S. (1976). Behavior analysis applied to environmental/ecological problems: A review. Journal of Applied Behavior Analysis, 9, 526.

Weigel, R. H., Vernon, D. T. A., \& Tognacci, L. N. (1974). Specificity of attitude as a determinant of attitude-behavior congruence. Journal of Personality and Social Psychology, 30, 724-728.

Wicker, A. W. (1969). Attitudes versus actions: The relationship of verbal and overt behavioral responses to attitude objects. Journal of Social Issues, 25, 41-78. 